\title{
Prevalence of Zoonotic Gastrointestinal Helminth Parasites (ZGIHP) of Dogs Presented to the Small Animal Clinic of the Veterinary Teaching Hospital, University of Agriculture, Makurdi, Benue State (October 2016-January 2017)
}

\author{
PER Msugh Felix \\ Department of Veterinary Public Health and Preventive Medicine \\ College of Veterinary Medicine, Federal University of Agriculture \\ Makurdi, Benue State, Nigeria \\ Perfelix2012@gmail.com \\ IKYE-TOR Philomina Mde \\ Department of Veterinary Public Health and Preventive Medicine \\ College of Veterinary Medicine, Federal University of Agriculture \\ Makurdi, Benue State, Nigeria \\ dvmde@yahoo.com \\ UWONDO, Aliko Emmanuel \\ Green Flash Veterinary Clinic \\ Makurdi, Benue State, Nigeria \\ uwondoemmanuel@gmail.com \\ ESONU, Daniel Obinna \\ Department of Veterinary Public Health and Preventive Medicine \\ Faculty of Veterinary Medicine, Ahmadu Bello University \\ Zaria, Kaduna State, Nigeria \\ Esonu25@gmail.com \\ DOI: $10.31364 / S C I R J / v 7 . i 8.2019 . P 0819686$ \\ http://dx.doi.org/10.31364/SCIRJ/v7.i8.2019.P0819686
}

\begin{abstract}
Dogs are the most common pet animals worldwide and have been reported to be hosts of many intestinal parasites of zoonotic importance globally. In Nigeria, gastrointestinal helminthes of dogs is currently endemic in 20 of the 36 states including Benue state.Out of 97 samples analysed $32(32.99 \%)$ were positive of at least one of the parasites over a period of 4 months (October 2016 - January 2017). There was higher occurrence of single infection 28(87.5\%) than concurrent mixed infections 4(12.5\%). The Helminth parasites recovered from dog's faeces were Ancylostoma caninum 30(30.93\%) and Dipylidium caninum $6(6.12 \%)$. There was no significant difference in prevalence with respect to age $(\mathrm{P}=0.300)$, breed $(\mathrm{P}=0.137)$, sex $(\mathrm{P}=0.538)$, month $(\mathrm{P}=0.443)$ and location $(\mathrm{P}=0.540)$. However, there was higher prevalence in young, local, male dogs.This study showed that there is high prevalence of ZGIHP of dogs in Makurdi. This can be a potential source of infection to other healthy dogs and humans.There is a need to continuously carryout public enlightenment campaign on the dangers of infection with helminthes by the appropriate agencies. A wider study should be carried out for a longer period to cover all seasons and possible dog ownership in the city.
\end{abstract}

Keywords: Helminths, Prevalence, Faecal samples, Makurdi, Nigeria.

\section{Introduction}

Zoonotic infections are infections of animals that are naturally transmissible to humans. As such they are worldwide and often spread to humans through their companion and domestic animals [1]. These diseases are receiving increasing attention from international community, as they account for $75 \%$ of newly emerging infectious diseases [2]. 
Parasitism is the most encountered disease in dogs all over the world [3]. Where studies have been conducted, parasitic gastrointestinal helmithes and protozoa have been identified as the major impediment to dog health worldwide owing to the direct and indirect losses they cause [4]. In addition, dogs are routinely infected with intestinal parasites, sometimes without apparent evidence of the infection until it is too late. This means that a dog can have internal parasites even though the faecal sample is negative, thus causing a health risk to humans [5].

The population of dogs as the most common pet and sentinel animal globally has been on a steady increase [6]. In areas of high population density such as urban and peri-urban, dog keeping practises may also be a risk to the transmission of zoonoses[7]. The major risk factors affecting epidemiology of helminthosis and other gastro-intestinal tract parasites can be classified broadly as parasite factors, host factors and environmental factors [8].

The transmission of zoonotic agents could be through direct contact with the animal, through indirect contact with animal secretions, excretions and infected water or food [9]. Many pet gastro-intestinal parasites eliminate their dispersion elements i.e egg or larvae by the faecal route [7].

Makurdi, the capital of Benue state Nigeria, is fast becoming a metropolitan centre with attendant health, social, housing and environmental problems. Dogs frequently roam and defaecate freely contaminating the environment with zoonotic parasites, a potential health hazard to the inhabitants. With an estimated population of three thousand, three hundred and twenty two street dogs and seven thousand five hundred owned dogs in Makurdi[10]. There is need therefore to carry out prevalence study of these parasites in dogs. This will enable health agencies to institute and evaluate control measures in order to control potential human infections.

II. Material and Methods

The study was conducted in the small animal Clinic of the Veterinary Teaching Hospital, University of Agriculture, Makurdi (VTHUAM) from October 2016 to January 2017. The town lies between latitude $7^{0} 15^{1}-7^{0} 45^{1} \mathrm{~N}$ and longitude $8^{0} 15^{1}-8^{0} 40^{1} \mathrm{E}$. The town lies in the guinea savannah vegetative belt and in the bank of the second largest river in Nigeria, River Benue. The river divides the town into north and south banks and the town covers an area of $16 \mathrm{~km}^{2}$. Makurdi has an altitude of 104 metres with an annual rainfall of about $1237 \mathrm{~mm}$ and mean annual temperature of $27.6^{\circ} \mathrm{C}$. It has a tropical wet and dry/savannah climate with a pronounced dry season in the low-sun months (Dec - March), no cold season, wet season in the high-sun months (April - Nov). Makurdi has an estimated population of 279,398 inhabitants according to 2006 population census with a projection of 348,990 at 2011 [11] with an average number of dogs per household at 1.43 [12].

Sample Collection

With the permission and assistance of the owners, faecal samples were collected from all the dogs presented to the Small Animal Clinic of the VTHUAM. Samples were collected directly from the rectum of the animals using a gloved hand and taken immediately to the Veterinary Parasitology Laboratory of VTHUAM for examination. Data with regard to breed, age, sex, location and date of sample collection was recorded for each animal that was sampled.

\section{LABORATORY PROCEDURE}

All faecal samples were examined on the same day of collection. Samples were initially examined microscopically for adult worms and proglottids. The presence of zoonotic helminthes infection was confirmed by simple floatation technique. Sodium chloride solution (0.18-0.2 SG) was used as flotation fluid and identification of eggs was made on the basis of their morphology using keys given by [13]. The preparation of a sample for simple flotation requires suspending $1 \mathrm{~g}$ of faeces in $15 \mathrm{ml}$ of flotation solution, straining that slurry through a sieve, and then pouring the strained fluid into a test tube. A coverslip was placed on top of the surface of the liquid and the tube and cover slipallowed to stand for another five minutes so that the eggs can passively float to the top of the solution. The coverslip was removed and placed on a clean glass slide for examination on a light microscope(x10) for the presence of helminths eggs [14]. 


\section{Results}

A total of 97 faecal samples were collected. Of these, zoonotic gastro-intestinal helminths parasites were detected in 32(32.99\%). Dogs with more than one species of the helminthes were taken as one positive case. There was higher occurrence of single infection $28(87.5 \%)$ than concurrent mixed infection 4(12.5\%). The Helminth parasites recovered from the faecal samples were Ancylostoma caninum 30 (30.93\%) and Dipylidium caninum 6 (6.12\%). Age specific prevalence rates were 38.18\% for dogs between 0-11 months, $21.43 \%$ for dogs between $1-4$ years and $35.71 \%$ for dogs above four years. Breed specific prevalence rates were $43.18 \%$ for local dogs, $16.67 \%$ for cross breed and $25.53 \%$ for the exotic breed of dogs. Sex specific prevalence rates were $34.72 \%$ for male dogs and $28.00 \%$ for the female dogs. Monthly distribution of prevalence rates were $34.78 \%$ in October, $47.06 \%$ in November, $25.00 \%$ in December and $31.03 \%$ in January. Gastro-intestinal Helminth parasites from dogs in different parts of Makurdi shows $36.73 \%$ in North bank, $30.00 \%$ in Wurukum, $42.86 \%$ in Modern market, $0.00 \%$ in Wadata and $28.57 \%$ in High level

Table 1: Age, breed and sex specific prevalence rates of zoonotic gasto-intestinal helminth parasites of dogs presented to the small animal clinic of the VTHUAM (October 2016 - January 2017)

$\begin{array}{lllll}\text { Number examined } & \text { Positive } & \text { Prevalence }(\%) & \mathrm{Chi}^{2} & \mathrm{P}\end{array}$

\begin{tabular}{|c|c|c|c|c|c|c|}
\hline & $0-1$ & 55 & 21 & 38.18 & & \\
\hline \multirow[t]{3}{*}{ Age } & $1-4$ & 28 & 6 & 21.43 & \multirow[t]{3}{*}{2.4106} & \multirow[t]{3}{*}{0.300} \\
\hline & $>4$ & 14 & 5 & 35.71 & & \\
\hline & Local & 44 & 19 & 43.18 & & \\
\hline \multicolumn{2}{|c|}{ BreedCrossed } & 6 & 1 & 16.67 & \multirow[t]{2}{*}{3.9732} & \multirow[t]{2}{*}{0.137} \\
\hline & Exotic & 47 & 12 & 25.53 & & \\
\hline Sex & Male & 72 & 25 & 34.72 & 0.3793 & 0.538 \\
\hline \multicolumn{2}{|c|}{ Female } & 25 & 7 & \multicolumn{2}{|l|}{28.00} & \\
\hline
\end{tabular}

Table 2: Monthly specific and location distribution prevalence rates of zoonotic gasto-intestinal helminth parasites of dogs presented to the small animal clinic of the VTHUAM (October 2016 - January 2017).

\begin{tabular}{|c|c|c|c|c|c|c|}
\hline & & Number examined & Positive & Prevalence $(\%)$ & $\mathrm{Chi}^{2}$ & $\mathrm{P}$ \\
\hline & October & 23 & 8 & 34.78 & & \\
\hline \multirow[t]{4}{*}{ Monthly } & November & 17 & 8 & 47.06 & 2.6852 & 0.443 \\
\hline & December & 28 & 7 & 25.00 & & \\
\hline & January & 29 & 9 & 31.03 & & \\
\hline & North bank & 49 & 18 & 36.73 & & \\
\hline
\end{tabular}




$\begin{array}{llllll}\text { Location } & \text { Wurukum } & 30 & 9 & 30.00 & \\ \text { Modern Market } & 7 & 3 & 42.86 & 3.1082 & 0.540 \\ \text { Wadata } & 4 & 0 & 00.00 & \\ \text { High level } & 7 & 2 & 28.57\end{array}$

\section{Discussion}

The study revealed a high level of infection with zoonotic gastrointestinal helminths (ZGIHP) in dogs presented to VTHUAM. This agrees with previous works in Nigeria with similar high prevalence [15, 16,17]. These findings affirm the potential environmental contamination with faeces of dogs which raises public health concern and constitutes health hazard to human population. The study like other previous studies $[18,19]$ has also shown more parasite eggs of Ancylostoma caninium. This could be due to the numerous modes of transmission of the parasite and better environmental factors that favour survival. The presence of high quantities of parasites eggs of dogs presented to the VTHUAM is a pointer that they are readily available sources of infection of these parasites to humans in the study area.

There was no significant difference in the prevalence of ZGIHP with respect to age $(\mathrm{P}=0.300)$. Although dogs below one year of age were more infected (38.18\%) and it decreased as the dog aged. The higher prevalence in young dogs as compared to older dogs agrees with [20]. This high prevalence could be as a result of the transmammary route of infection and age-acquired dependent immunity may be caused by repeated exposure [21]. The decrease on older dogs may be due to specific immune response to the parasite exposed to the dogs at early ages [22].

With respect to breeds, there was also no significant difference in the prevalence of ZGIHP (P=0.137). The higher prevalence noted in local breeds $(43.18 \%)$ may be due to their scavenging habits which increases their risk of acquiring the parasites from the environment. The crossed and exotic breeds which may be less immune are usually more treasured and restricted by their owners and therefore less prone to infection. This agrees with [23] who posits that the degree of care shown to pets is closely related to their owners and on the breed of pet.

The study revealed no statistically significant difference $(\mathrm{P}=0.538)$ in the frequency of ZGIHP of dogs between male and female dogs. This finding agrees with [24, 25]. However, the higher prevalence observed in male dogs (34.72\%) agrees with [26] and this may be due to the more scavenging and hunting nature of male dogs.

With respect to locations sampled, Modern market (42.86\%) and North bank (36.73\%) had higher prevalence than High level $(28.57 \%)$ and Wurukum (30.00\%), however, this difference was not statistically significant $(\mathrm{P}=0.54)$. The higher prevalence in the first two locations could be as a result of the high disparity in numbers of samples collected from these two places.

\section{Conclusion}

The high prevalence recorded in this study calls for a sustained control and preventive efforts to minimise the worm burden in these animals. Considering the fact that these are owned dogs presented to the clinic rather than the unowned/free roaming dogs with much higher risk of infection with ZGIHP. Parasites infections are known to be a hazard for people exposed to contaminated environment. This poses a considerable potential risk of transmission to humans in the study area.It is therefore important that dog owners take their dogs to Veterinary clinics for routine check up. Public enlightenment campaign should be carried out by appropriate agencies on the risk associated with environmental contamination with helminths eggs of dogs.

\section{Acknowledgment}

We deeply appreciate the Director and the staff of the Parasitology laboratory of the Veterinary Teaching Hospital, University of Agriculture, Makurdi for their permission and assistance in the course of this work. 
References

[1] Goldsmid J,(2005). Zoonotic Infections- $\quad$ an $\quad$ overview.Chapter 14; 14.14.http://www.troponed.org/primer/chapter14,pdf.

[2] Tenguria, R. K., Khan, F. N., Quereshi, S. and Pandey, A.(2011). Epidemiology Study of Zoonotic Tuberculosis World Journal of Science and Technology 1(3): 31-56.

[3] Zelon, D. B. (2003). Dogs, Humans and Gastrointestinal Parasites; Unraveling Epidemiology and Zoonotic Relationships in an endemic tea-growing community in Northeast India. Doctoral dissertation Murdoch Universit

[4] Smith, R. D(1991). Veterinary Clinical Epidemiology. Butterworth-Heinmann, Boston, Pp: 228

[5] Craig, P.S., and Macpherson, C. N.(2000). Dogs and CestodeZoonoses. In: Dogs Zoonoses and Public Health (Macpherson CN, Mesli FX, Wandeler AL Eds), CAB International, Oxon, United Kingdom: 149-221.

[6] Kornbalt, A.N, and Schantz, P. M. (1980). Veterinary and public Health consideration in canine roundworm control: A survey of practising veterinarians.Journal of American Medical Association. 137: 1212-1215.

[7] Khante, G. S, Khan, L. A., Bodkhe, A. M., Suryawamshi, P. A., Majed, M. A, Surdkar, U. S, and Gaikwad, S.S. (2009). Epidemiological survey of Gastrointestinal parasites of non-descript dogs in Nagpur city. Veterinary world 2(1): 22-23.

[8] Thrusfield, M. V. (2005). Veterinary Epidemiology 3rd edition. Blackwell Science, Oxford, pp. $234-238$.

[9] Bugg, R. J., I. D. Robertson, A. D. Elliot and R. C. A. Thomson. (1999).Gastrointestinal Parasites of Urban dogs in Parth, Australia Veterinary Journal, 157-301.

[10] Akombo, P.M. UmohJ.U. Ajogi I. and Bello M. (2009). Dog ecology and epidemiological studies of canine rabies in Makurdi, Benue State.M.sc. thesis.Ahmadu Bello University, Zaria, Nigeria.

[11] Nigeria, National Population Commision (Benue State), 2006.

[12] Omudu, E. A., Otache, E. O., Adelusi, S. M.(2010). Studies on dog population in makurdi, Nigeria; Demography and survey of pet owners belief and attitudes. In journal of Research in forestry; Wildlife and environment. Vol 2 No. 1.

[13] Sousby, E.J.L., (1982).Helminths, Arthropods and Protozoa of Domesticate Animals, $7^{\text {th }}$ edn Lea \&Lebiger, Philadelphia, PA, pp.203-206.

[14] Zajac A.M. (1994).Fecal examination in the diagnosis of parasitism. In: ZajacAM, ed. Veterinary clinical parasitology. 6th ed. Ames: Iowa State University Press; 3-93

[15] Adamanyi, C.O., Omudu E. A.(2016). Prevalence of gastro-intestinal Helminth of faeces from in-door dogs and stray-dogs in Makurdi, Nigeria; In Nigeria Journal of Parasitology. Vol 37, No 1.

[16] Ogbaje, C. I., Ofukwu, R. A., and Ajogi, L. A. (2015). Zoonotic Gastrointestinal Parasite burden of local dogs in Zaria, Northern Nigeria: Implications for human health. International Journal of one health 1: 32-36.

[17] Adeniyi, I.C., Morenikeji, O.A. and Emikpe, B.O. (2014). The prevalence of carnivores in university zoological gardens in south west Nigeria: In Journal of Veterinary Medicine and Animal Health. 2:136-139.

[18] OkohA.E.J, Per M.F, and Du-saiDHM(2016). A retrospective Study of Toxocaracanis at the Veterinary Teaching Hospital, UAM, Nigeria. Vom Journal of Veterinary Science 11:152-154.

[19] Umoh, J. U. and Asake, T.T.(1982). Prevalence of Gastrointestinal Helminth parasites of dogs in Ibadan, Nigeria.Nigeria Veterinary journal. 11(2).p.2

[20] GiriD.R. (2010). Screening of Zoonotic helminths in canines of Kathmandu district brought to Central Veterinary Hospital, Tripureshwor (unpublished dissertation). Institute of Agriculture and Animal Science, Tribhuvan University, Nepal.

[21] Susan E.L., Eileen M.J., David L., RenueP.J., Mark E.P., Bryon L., BlagburnD.D., Bowman S., MoroffT.D. and Tams L. (2009). Prevalence of intestinal parasites in pet dogs in the United States.Veterinary Parasitology 166(1-2):144-52.

[22] Onyenwe, I. W., and Ikpegbu E. O. (2004). Prevalence of gastrointestinal Helminth parasites of dogs presented at the University of Nigeria Veterinary Hospital (UNVTH) between 1994-2002. Nigerian Veterinary Journal. 25(1):21-25.

[23] Omamegbe, J. O (1980). A survey of dogs and their owners seen at Two Veterinary Clinics in Enugu and Nsukka Areas of Anambra State, Nigeria.Nigeria Veterinary Journal, 9:10-16.

[24] YacobH.T, Ayele T, Fikru R, BasuA.K (2007). Gastrointestinal nematodes in dogs from DebreZeit, Ethiopia.Veterinary Parasitology.148: 144-148.

[25] FontanarrosaM.F, Vezzani D, Basabe J, EirasD.F (2006). An epidemiological study of gastrointestinal parasites of dogs from Southern Greater Buenos Aires(Argentina): age, gender, breed, mixed infections, and seasonal and spatial patterns. Veterinary Parasitology 136: 283-295.

[26] Dagmawi P, Mekonnen A., Abebe F. and Berhanuu M. (2012). Prevalence of Gastrointestinal helminthes among dogs and owners perception about zoonotic dog parasites in Hawassa Town, Ethiopia.Journal of Public Health and Epidemiology. 12: 205-209. 